\title{
SIMULATION BASED ANALYSIS OF QUASI Z-SOURCE CONVERTER FOR WIRELESS POWER TRANSFER
}

\author{
Kaspars Kroics \\ Riga Technical University, Latvia \\ kaspars.kroics@gmail.com
}

\begin{abstract}
Implementation of Wireless Power Transfer (WPT) allows avoid connection by using wires to transfer energy between the power source and load. This allows development of devices that are more users friendly and easy in the exploitation. Elimination of the galvanic connection between the charging station and the energy consumer simplifies the charging process and removes safety concerns. In this paper an insight is given into basics of WPT theory to show why often an additional DC-DC converter at the WPT converter input is used and why the Z-source converter can be useful for this application. It is explained why application of an additional converter can give additional increase of the efficiency. The paper presents deeper analysis of scientific papers about Z-source network application in WPT systems that allows eliminate utilization of the additional converter but allows to regulate the input voltage. In the paper simplified explanation of quasi Z-source converter operation in boost mode is given. Based on this explanation it is easier to understand operation of the quasi Zsource converter and usefulness of application of this topology in WPT applications. Simulation of the quasi Zsource based WPT converter is performed and the simulation resulting waveforms show that it is possible to regulate the DC bus voltage and supply the energy to the system output with Z-source based WPT simultaneously, without adding extra semiconductor devices and very complex control circuitry to the conventional WPT system. These simulation results show that the quasi Z-source converter for WPT can regulate the DC bus voltage and transfer power to the load with relatively simple control. The waveforms of the control signals and current, and voltage waveforms are given. The Z-source topology analysed in this paper offers significant benefits, therefore, scientific research to improve and optimize this topology is needed further in order to meet the EMI standards, reduce switching losses with implementation of soft switching, optimize passive components, develop new control strategies and to increase the system efficiency. By overcoming these issues, the Z-source topology can become very attractive for WPT systems.
\end{abstract}

Keywords: wireless power transmission, impedance source, topology, power electronics, converter, resonance.

\section{Introduction}

The main benefit of WPT implementation is that no wire is needed anymore to transfer energy between the power source and load. This allows building devices that are more users friendly and easy in the exploitation. Elimination of the galvanic connection between the charging station and the energy consumer simplifies the charging process and removes safety concerns. The WPT system must comply with the relevant safety standards for the magnetic field. The WPT technology finds its application in electrical vehicles [1-5], electronic gadgets charging [6;7] medical applications [8] and in many other applications. Promising WPT application is dynamic charging of the electric vehicles [9] by placing WPT transceiver side under the road. Such approach allows increasing of the electric vehicle market, because in such a way the energy storage capacity requirement can be reduced and the range limit of electric vehicles extended.

Radiation based WPT is more suitable for low power transfer. Non-radiation based WPT technologies are two - inductive power transfer that is used very widely and capacitive power transfer [10]. A good comparison between both technologies is given in [11], the capacitive power transfer is more suitable for smaller air gap and lower power in comparison with the inductive power transfer. The new wide band gap semiconductor device allows increasing the switching frequency, therefore capacitive power transfer can be applicable for higher power transfer in near future. The typical power management concept of the WPT system in case when the electrical energy is supplied from the AC grid is shown in Fig. 1. As it can be seen in the figure, usually there is needed an additional DC-DC converter, Power Factor Corrector (PFC) and often also a DC-DC converter at the output. The most effective power transfer is possible in case, if the transmitter coil receives voltage with its resonance frequency and the receiver coil resonance frequency is tuned to the same frequency, this is a complicated task and therefore there is used an additional DC-DC converter to manage the power flow. If the load is constant, the additional DC-DC converter at the output is optional. As usually WPT is used to charge battery, the additional DC-DC converter is used. 


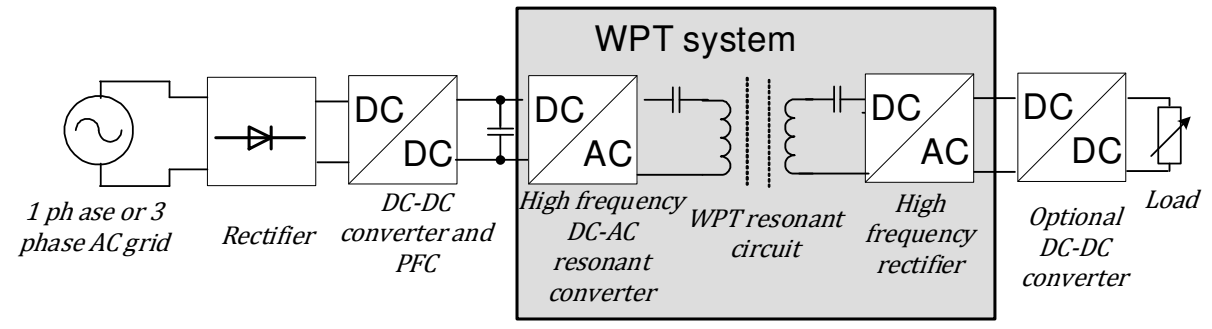

Fig. 1. Basic power management concept of Wireless Power Transfer (WPT) system

The single-stage topology of the converter gives a possibility to use a lower number of semiconductor devices and potentially increases the efficiency. One of the potential topologies is the Z-source inverter [12] that can be applied to any kind of power conversion between DC and AC. A combination of $Z$ source network and resonant circuit has been studied in $[6 ; 13 ; 14]$. It can improve the efficiency over a wide input voltage and load variation [14]. In this paper scientific papers will be analyzed about using of Z-source based topologies into WPT system, benefits and drawbacks of using such topology into WPT. Also, in the paper basic mathematical equations will be given and some analysis will be based on the PSIM software model.

\section{WPT system design basics}

The typical WPT converter is very similar to the isolated DC-DC converter, but the most significant difference is that the transformer has significantly higher leakage inductance and lower magnetizing inductance. To transfer power with a high efficiency the inductive power transfer coils are operated in a resonant converter topology with additional capacitors on the primary and secondary side for compensation of the large leakage inductance. The resonant network can be build using several combinations of capacitors and inductors, the most commonly used are the series-series, series-parallel and the series-series-parallel compensation networks [15]. As the series-series compensation network in combination with a full bridge converter is good compromise between the complexity and efficiency, it will be analyzed further.

The typical topology of the series-series compensated WPT system is shown in Fig. 2. The series resonant primary side is powered by a full-bridge inverter. At the secondary side a full bridge rectifier is used to convert the $\mathrm{AC}$ voltage into $\mathrm{DC}$ output voltage, the power flow to the load often is controlled by an additional non-isolated DC-DC converter. Very important element in WPT system is the air-core transformer, it has large leakage inductance and very low magnetizing inductance and the coupling coefficient $(k)$ between the transmitter and receiver coils is extremely poor. The most effective power transfer is possible, if the transmitter coil receives a voltage with its resonance frequency and the receiver coil resonance frequency is tuned to the same frequency. The resonance frequency can be calculated by well-known equation:

$$
f_{\text {res }}=\frac{1}{2 \pi \sqrt{L C}},
$$

where $L$ - inductance of the WPT coil, $\mathrm{H}$;

$C$ - capacitance of the series resonance network, F.

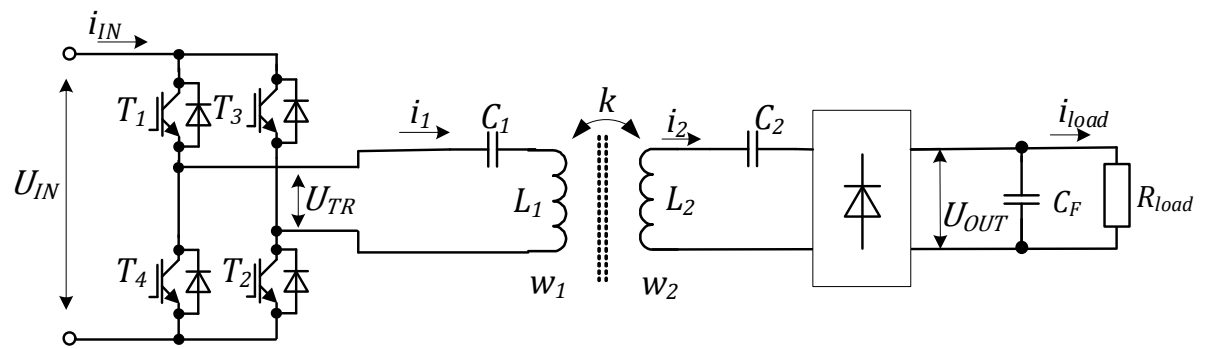

Fig. 2. Typically used series-series resonant topology of WPT system 
In [16] it is shown that the maximum efficiency of the wireless energy transmission considering the power losses in the energy transmission coils only, can be approximated as follows:

$$
\eta_{\max }=1-\frac{2}{k \sqrt{Q_{1} Q_{2}}},
$$

where the coil coupling coefficient $(k)$ and the coil quality factors $(Q)$ are calculated as follows:

$$
\begin{gathered}
k=\frac{M}{\sqrt{L_{1} L_{2}}}, \\
Q_{i}=\frac{\omega L_{i}}{R_{i}},
\end{gathered}
$$

where $M$ - mutual inductance between both coils, $\mathrm{H}$;

$Q_{1}, Q_{2}$ - quality factors of the primary and secondary coil respectively.

Simplified transformer equivalent circuit of the WPT transformer is shown in Fig. 3. In the figure is shown a case, when the number of windings of the primary side and secondary side coils is equal, if the number of windings is different of both windings, then the equivalent circuit becomes more complex. Circuit shown in Fig. 3 can be mathematically described by the following equations:

$$
\begin{aligned}
& u_{1}=\left(L_{1}-M\right) \frac{d i_{1}}{d t}-M \frac{d\left(i_{1}-i_{2}\right)}{d t}, \\
& u_{2}=M \frac{d\left(i_{1}-i_{2}\right)}{d t}-\left(L_{2}-M\right) \frac{d i_{2}}{d t} .
\end{aligned}
$$

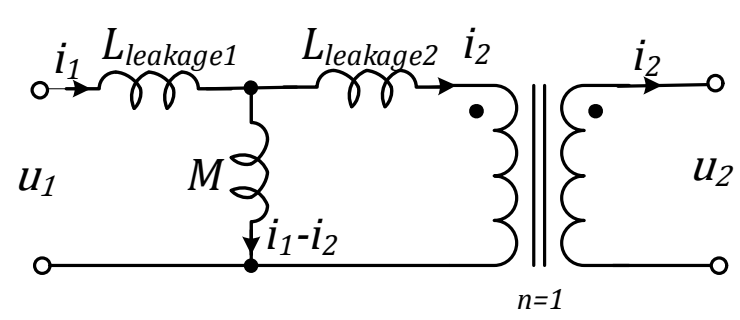

Fig. 3. Simplified (transformer coefficient $n=1$ ) equivalent circuit of air transformer

According to [17] the load together with the full-wave rectifier can be replaced by equivalent load $R^{\prime}{ }_{\text {load }}$ :

$$
R_{\text {load }}^{\prime}=\frac{8}{\pi^{2}} \frac{U_{2}^{2}}{P_{2}} .
$$

Fig. 4 shows a voltage gain example of the WPT system. As it can be seen, the converter optimal working frequency is narrow, changing the load or air gap significantly influences the WPT transfer characteristics and therefore the control loop of the converter is very important to ensure efficient operation of the WPT converter. For the series-series compensation circuits, the resonant capacitor can be chosen to compensate all inductance of the primary and secondary side:

$$
C_{i}=\frac{1}{\omega_{r e s}^{2} L_{i}},
$$

or to compensate just leakage inductance of both coils:

$$
C_{i}=\frac{1}{\omega_{\text {res }}^{2} L_{i}(1-k)} .
$$

The series-series compensated system operated at the resonant frequency and with all inductance compensation can achieve the highest power conversion efficiency, but requires a higher complexity 
of the control system, an additional DC-DC converter at the load side is required, as operation at the optimum is possible at such condition:

$$
U_{2}=\sqrt{\frac{\pi^{2}}{8} P_{2} k \omega_{r e s} L_{2}} .
$$

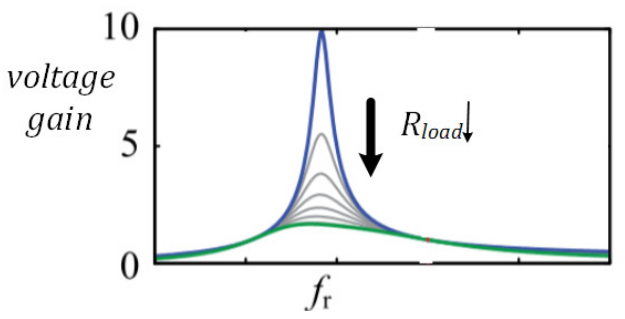

Fig. 4. Voltage gain of series-series compensated WPT [18] at optimal coupling coefficient to get highest voltage gain

The compensation of only leakage inductances of the air transformer gives a possibility to use a more simple control , but suffers from large reactive power on the primary side at low coil coupling, which limits the power transfer capability at large coil separation distances [15]. An important factor that should be considered by designing of the WPT system is standards - operating frequency limitations, EMI and magnetic field limitations. If the WPT system is located in an area accessible by the public, it must not only comply with the relevant safety standards for electromagnetic fields, but also the consumer should be confronted with little or no additional effort in using the contactless charger.

\section{Z-source based converter for WPT}

Fig. 5 shows schematics of the quasi Z source resonant converter for WPT, it consists of the impedance network, four semiconductor switches, primary side and secondary side resonant circuits, full bridge rectifier and the air core transformer that is replaced by equivalent circuit in Fig. 5. The converter is controlled by means of full bridge inverter transistors and only one additional diode or transistor is needed to provide operation of the converter. Two inductors and capacitors form the quasi $\mathrm{Z}$ source network and by means of shoot through state duty cycle $(D)$ voltage $\mathrm{U}_{\mathrm{DC}}$ and $\mathrm{U}_{\mathrm{TR}}$ can be controlled.

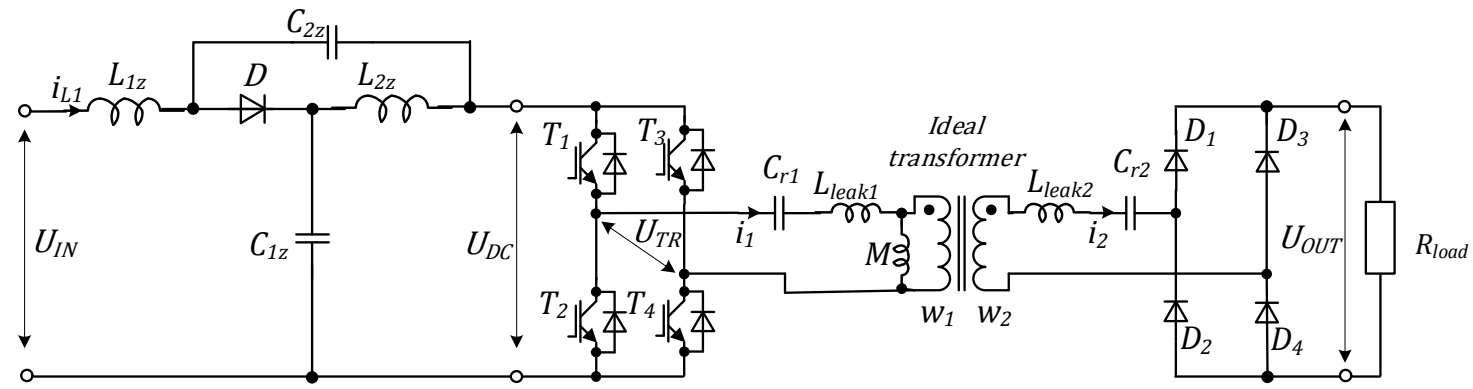

Fig. 5. Quasi $Z$ source resonant converter for WPT

There are several topologies of the impedance network ( $\mathrm{Z}$ source) that can be used, the quasi $\mathrm{Z}$ source topology allows eliminate discontinuous current mode that in many cases gives advantages. Quasi Z source network more often is used in DC-DC converters [19-24] or in DC-AC inverters to produce sinusoidal voltage [25-27]. The Z-source or quasi Z-source converters for WPT are analyzed in [28-33], the converter is used for both inductive and capacitive power transfer, also for Power Factor Correction (PFC) [34]. In these scientific papers also practical results are demonstrated on small scale experimental prototypes, but high efficiency of such converter is not reported. Also, all of these researches and prototypes are far from industrial application. The main benefit of using Z-source based converters for WPT is that without an additional DC-DC converter the power factor can be controlled or the DC voltage regulated to maximize the efficiency of the WPT stage. The control of 
the converter becomes more complex and therefore such approach is not widely used and mainly used for scientific purposes only till today.

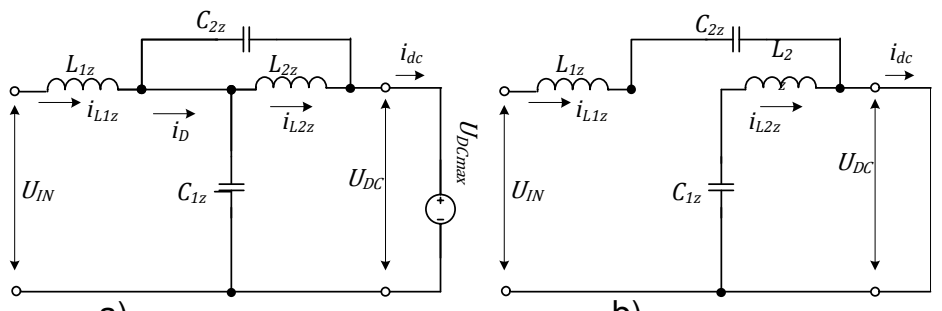

a)

b)

Fig. 6. Equivalent circuits of converter: a - during non shoot-through state;

$$
\mathrm{b} \text { - during shoot-through (ST) state }
$$

The operation modes of the simplified converter model are shown in Fig. 6. From the equivalent circuit expressions can be derived that describe voltages and currents in particular state:

$$
\begin{gathered}
L_{1 z}=\frac{d i_{L_{1 Z}}}{d t}=u_{I N}-u_{C_{1 z}}, \\
L_{2 z}=\frac{d i_{L_{2 Z}}}{d t}=-u_{C_{2 z}}, \\
C_{1 z}=\frac{d u_{C_{1 Z}}}{d t}=i_{L_{1 z}}-i_{d c}, \\
C_{2 z}=\frac{d u_{C_{2 Z}}}{d t}=i_{L_{2 z}}-i_{d c} .
\end{gathered}
$$

During the ST state, the circuit equations are as follows:

$$
\begin{gathered}
L_{1 z}=\frac{d i_{L_{1 Z}}}{d t}=u_{I N}+u_{C_{2 z}}, \\
L_{2 z}=\frac{d i_{L_{2 Z}}}{d t}=u_{C_{1 z}}, \\
C_{1 z}=\frac{d u_{C_{1 Z}}}{d t}=-i_{L_{1 z}}, \\
C_{2 z}=\frac{d u_{C_{2 Z}}}{d t}=-i_{L_{1 z}} .
\end{gathered}
$$

The relation between variables of the converter can be described mathematically by solving equations that describe both states of the converter and taking into account that average voltage of an inductor over one switching period is zero and also average current of a capacitor over one switching period is zero. So, to derive these equations it is assumed that currents in the inductors and voltages of the capacitors have low ripples. Expressions are relatively simple and can be solved analytically. It must be taken into account that in equations parasitic resistances of all elements are not taken into account, the final equations for steady-state conditions are as follows:

$$
\begin{aligned}
& U_{C 1 z}=\frac{1-D}{1-2 D} U_{I N}, \\
& U_{C 2 z}=\frac{D}{1-2 D} U_{I N},
\end{aligned}
$$




$$
U_{D C \max }=\frac{1}{1-2 D} U_{I N},
$$

where $D$ - duty cycle is relationship between the ST state and the switching period.

As Eq. 21 shows, by controlling of shoot through the duty cycle it is possible to control the input voltage of the WPT converter; that means it is possible to optimize the efficiency of the WPT converter, implement PFC functionality, it is easier to maintain that the WPT converter works at resonant frequency and frequency deviation during the operation is small. In this case the ST duty cycle $D$ can be changed from 0 to 0,5 correspondingly increasing the input voltage of the WPT converter.

\section{Simulation of Z-source converter based WPT system}

Fig. 7 shows the simulation results of a traditional WPT system with a full bridge converter shown in Fig. 2. The theoretical model of the air transformer in simulations is used with the coupling coefficient k from 0.3 to 0.7 and inductance of the primary and secondary side equal to $20 \mu \mathrm{H}$, the output capacitor value that is connected in parallel to load is equal to $100 \mu \mathrm{F}$, switching frequency equal to $100 \mathrm{kHz}$. As it can be seen in the figure, the voltage $U_{T R}$ that is applied to the resonant tank has amplitude equal to DC bus voltage (in this case 100V), whereas in case of the quasi Z-source converter (schematics is shown in Fig. 5) this voltage can be controlled by means of shoot through duty cycle. It means in this case to stay close to resonance mode it is needed to change the switching frequency that will lead to complicate algorithm how to maintain the resonance conditions. Also, by increasing the switching frequency the switching losses can be increased. In case, if the WPT system is powered from the AC grid, the power factor correction (PFC) functionality is not possible and therefore an additional PFC converter is required.

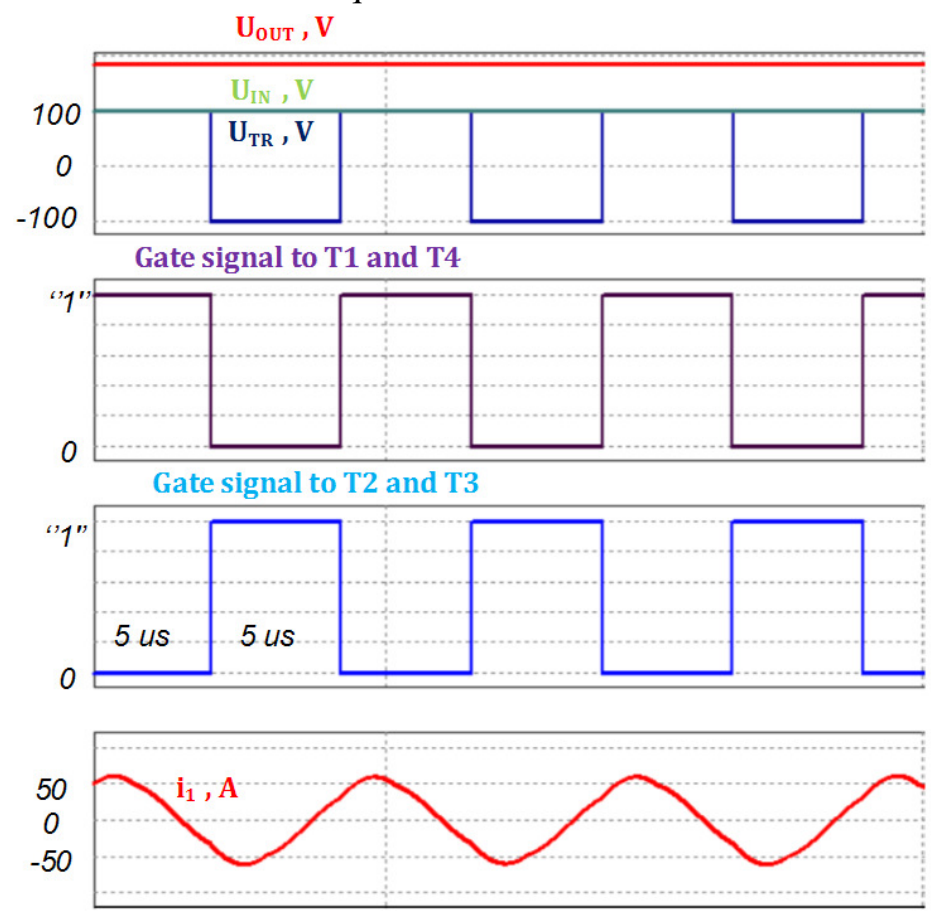

Fig. 7. PSIM simulation of traditional WPT system

To ensure that the quasi Z-source converter can be used for the WPT system, the schematic shown in Fig. 5 was simulated in PSIM software. The Z-source inductances of the quasi Z source resonant converter $L_{1 z}, L_{2 z}$ is equal to $200 \mu \mathrm{H}$, but the capacitors $C_{1 z}, C_{2 z}$ to $2 \mathrm{mF}$. The calculation of the quasi Z-source parameters is given in many papers, for example, in [35;36]. The values of these passive components can be optimized, the capacitors have so large capacitance as the operation of the converter was also tested for rectified AC voltage to ensure PFC functionality. In case of a conventional WPT system anyway the rectifier and bulky capacitor will be needed to compensate $50 \mathrm{~Hz}$ voltage ripple. The theoretical model of the air transformer in simulations is used with the 
coupling coefficient $k$ from 0.3 to 0.7 and inductance of the primary and secondary side equal to $20 \mu \mathrm{H}$, the output capacitor value that is connected in parallel to load is equal to $100 \mu \mathrm{F}$. The optimization of the WPT transformer shape, number of windings, construction and so on is a complicated task [16] and is not analyzed in this paper. The switching frequency is selected equal to $100 \mathrm{kHz}$. The duty cycle D can be controlled by using feedback algorithm to control the value of voltage $\mathrm{U}_{\mathrm{TR}}$. It is possible to implement control algorithm that maintains that this voltage is controlled in such a way that by change in the load power this voltage is changed to maintain the resonance conditions and to keep the load voltage to the desired level. The simulation of the quasi Z-source based WPT converter is shown in Fig. 8.

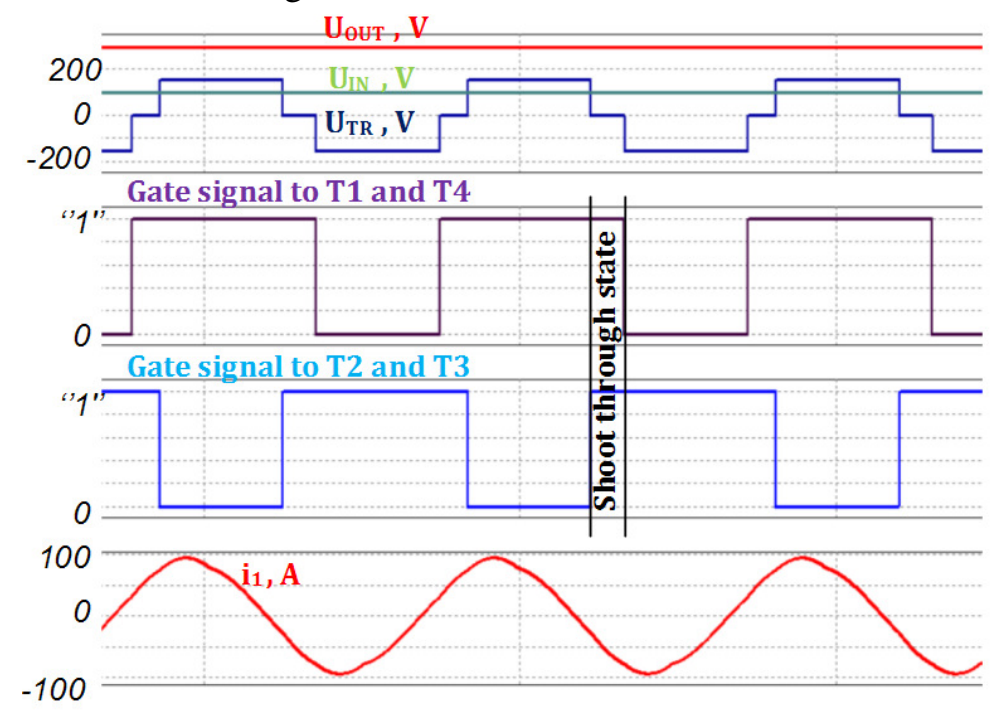

Fig. 8. PSIM simulation of quasi $Z$ source based converter for $W P T, T=10$ us, $D=0,1$

As it can be seen in Fig. 8, by changing the length of the shoot through state it is possible to regulate the voltage $U_{T R}$, therefore, operation more close to the resonance frequency is easier to realize. As it can be seen, the resonant tank current is sinusoidal and therefore such topology does not reduce the efficiency of the wireless power transfer process significantly. The simulations show that larger power can be transferred to the load. But on the other side, the shoot through state influences the voltage shape that also can cause undesirable operation mode. The impedance network itself has its own resonance frequency, so it is necessary to make deeper analysis to prevent undesirable oscillations in this impedance network. Also, there are needed two control loops - one to control the DC bus voltage via changing the shoot through duty cycle and the second to control the energy flow through the resonant network and air gap transformer. By using the quasi-Z-source converter in combination with the WPT converter, it is possible to reduce the number of semiconductor devices comparing with a case, when an additional DC-DC converter is used to regulate the input voltage of the WPT converter or to maintain the PFC functionality.

\section{Conclusions}

This paper focuses on the possibility of using the quasi Z-source converter for WPT application and the benefits from such approach. The theory of WPT shows that one of the challenges is the design of the converter that works in resonant frequency in a wide load range. It is explained why it is important to work close to the resonant conditions. To simplify the control system and design of the WPT system often an additional DC-DC converter at the input side is used. This converter can be eliminated in case, if the Z-source based WPT system is used. The operation of the quasi Z-source converter is revealed based on mathematical equations. The simulation results show that the quasi Zsource converter for WPT can regulate the DC bus voltage and transfer power to the load with relatively simple control - by using an additional PI control loop for the ST duty cycle. The shoot through state changes the shape of the voltage on the resonant tank and therefore more advanced control method can be required. At the same time, the Z-source topology offers significant benefits as the number of semiconductor devices can be reduced, therefore, scientific research to improve and optimize this topology is needed in order to meet the EMI standards, reduce switching losses with 
implementation of soft switching, optimize passive components, develop new control strategies and so on, to increase the system efficiency. By overcoming these issues, the Z-source topology can become very attractive for WPT systems.

\section{References}

[1] Mou X., Groling O., Sun H. Energy-Efficient and Adaptive Design for Wireless Power Transfer in Electric Vehicles. IEEE Transactions on Industrial Electronics, vol. 64, no. 9, 2017, pp. 72507260 .

[2] Mohamed A. A. S., Lashway C. R., Mohammed O. Modeling and Feasibility Analysis of QuasiDynamic WPT System for EV Applications. IEEE Transactions on Transportation Electrification, vol. 3, no. 2, 2017, pp. 343-353.

[3] Saltanovs R. Multi-capacitor circuit application for the wireless energy transmission system coils resonant frequency adjustment. Proceedings of "IEEE Wireless Power Transfer Conference" (WPTC), June 3-7, Montreal, Canada, 2015, pp. 1-3.

[4] Li S., Mi C. C. Wireless Power Transfer for Electric Vehicle Applications. IEEE Journal of Emerging and Selected Topics in Power Electronics, vol. 3, no. 1, 2015, pp. 4-17.

[5] Kroics K., Zakis J., Suzdalenko A., Gaigals G. A simplified approach to input voltage balancing for series connected isolated DC-DC converters. Proceedings of "18th European Conference on Power Electronics and Applications", September 5-9, Karlsruhe, Germany, 2016, pp. 1-10.

[6] Pakhaliuk B., Husev O., Shevchenko V., etc. Novel Inductive Power Transfer Approach Based on Z-Source Network with Compensation Circuit. Proceedings of "IEEE Conference on Electronics and Nanotechnology" (ELNANO), April 24-26, Kyiv, Ukraine, 2018, pp. 699-704.

[7] Kroics K., Husev O., Pakhaliuk B., Zakis J., Velihorskyi O., Strzelecki R. Single Switch MultiWinding Wireless Power Transfer System Based on Z-Source Network. Proceedings of 20th European Conference on Power Electronics and Applications (EPE'18 ECCE Europe), September 17-21, Riga, Latvia, 2018, p. P.1-P.9.

[8] Knecht O., Bosshard R., Kolar J. W., Starck C. T. Optimization of Transcutaneous Energy Transfer coils for high power medical applications. Proceedings of "IEEE Workshop on Control and Modeling for Power Electronics" (COMPEL), June 22-25, Santander, Spain, 2014, pp. 1-10.

[9] Liu Y., Mai R., Liu D., Li Y., He Z. Efficiency Optimization for Wireless Dynamic Charging System with Overlapped DD Coil Arrays. IEEE Transactions on Power Electronics, vol. 33, no. 4, 2017, pp. 2832-2846.

[10]Li S., Liu Z., Zhao H., Zhu L., Shuai C., Chen Z. Wireless Power Transfer by Electric Field Resonance and Its Application in Dynamic Charging. IEEE Transactions on Industrial Electronics, vol. 63, no. 10, 2016, pp. 6602-6612.

[11] Dai J., Ludois D. C. A Survey of Wireless Power Transfer and a Critical Comparison of Inductive and Capacitive Coupling for Small Gap Applications. IEEE Transactions on Power Electronics, vol. 30, no. 11, 2015, pp. 6017-6029.

[12] Roasto I., Jalakas T., Husev O. Modeling of grid-connected quasi-Z-source series resonant topology based microinverter. Proceedings of "10th International Conference on Compatibility, Power Electronics and Power Engineering” (CPE-POWERENG), 2016, pp. 192-195.

[13] Vinnikov D., Chub A., Liivik E., Roasto I. High-Performance Quasi-Z-Source Series Resonant DC-DC Converter for Photovoltaic Module-Level Power Electronics Applications. IEEE Transactions on Power Electronics, vol. 32, no. 5, 2017, pp. 3634-3650.

[14] Cha H., Peng F. Z., Yoo D. Z-source resonant DC-DC converter for wide input voltage and load variation. Proceedings of "International Power Electronics Conference" (ECCE ASIA), June 2124, Sapporo, Japan, 2010, pp. 995-1000.

[15] Knecht O., Bosshard R., Kolar J. W., Starck C. T. Optimization of Transcutaneous Energy Transfer coils for high power medical applications. Proceedings of "IEEE Workshop on Control and Modeling for Power Electronics" (COMPEL), June 22-25, Santander, Spain, 2014, pp. 1-10.

[16] Bosshard R., Mühlethaler J., Kolar J. W., Stevanović I. The $\eta$ - $\alpha$-Pareto front of inductive power transfer coils. Proceedings of "38th Annual Conference on IEEE Industrial Electronics Society" (IECON 2012), October 25-28, Montreal, Canada, 2012, pp. 4270-4277.

[17] Steigerwald R. L. A comparison of half-bridge resonant converter topologies. IEEE Transactions on Power Electronics, vol. 3, no. 2, 1988, pp. 174-182. 
[18] Knecht O., Bosshard R., Kolar J. W. High-Efficiency Transcutaneous Energy Transfer for Implantable Mechanical Heart Support Systems. IEEE Transactions on Power Electronics, vol. 30, no. 11, 2015, pp. 6221-6236.

[19] Matiushkin O., Husev O., Tytelmaier K., Kroics K., Veligorskyi O., Zakis J. Comparative Analysis of qZS-Based Bidirectional DC-DC Converter for Storage Energy Application. Proceedings of "Advanced Doctoral Conference on Computing, Electrical and Industrial Systems" (DoCEIS 2017), May 3-5, Costa de Caparica, Portugal, 2017, pp. 409-418.

[20] Chub A., Husev O., Zakis J., Rabkowski J. Switched-capacitor current-fed quasi-Z-source inverter. Proceedings of "14th Biennial Baltic Electronic Conference" (BEC), October 6-8, Tallin, Estonia, 2014, pp. 229-232.

[21] Chub A., Liivik L., Vinnikov D., Zakis J. Asymmetrical PWM control of galvanically isolated impedance-source series resonant DC-DC converters. Proceedings of "10th International Conference on Compatibility, Power Electronics and Power Engineering" (CPE-POWERENG), June 29 - July 1, Bydgoszcz, Poland, 2016, pp. 341-346.

[22]Liivik L., Chub A., Vinnikov D., Zakis J. Experimental study of high step-up quasi-Z-source DCDC converter with synchronous rectification. Proceedings of "9th International Conference on Compatibility and Power Electronics" (CPE), 24-26 June, Costa da Caparica, Portugal, 2015, pp. 409-414.

[23] Kroics K., Zakis J. Electronic Ballast for Gas Discharge Lamp Based on Input-Series OutputSeries Resonant Converter. Proceedings of "International Exhibition and Conference for Power Electronics, Intelligent Motion, Renewable Energy and Energy Management" (PCIM Europe 2017), May 16-18, Nuremberg, Germany, 2017, pp. 1-7.

[24] Kroics K., Sokolovs A., Sirmelis U., Grigans L. Interleaved series input parallel output forward converter with simplified voltage balancing control. Proceedings of "International Exhibition and Conference for Power Electronics, Intelligent Motion, Renewable Energy and Energy Management" (PCIM Europe 2016), May 10-12, Nuremberg, Germany, 2016, pp. 1-8.

[25] Makovenko E., Husev O., Roncero-Clemente C., Romero-Cadaval E., Vinnikov D. Three-level single-phase quasi-Z source inverter with active power decoupling circuit. Proceedings of "18th International Conference of Young Specialists on Micro/Nanotechnologies and Electron Devices" (EDM), June 29 - July 3, Erlagol, Russia, 2017, pp. 497-502.

[26] Makovenko E., Husev O., Zakis J., etc. Passive power decoupling approach for three-level singlephase impedance Source Inverter based on resonant and PID controllers. Proceedings of "11th IEEE International Conference on Compatibility, Power Electronics and Power Engineering" (CPE-POWERENG), April 4-6, Cadiz, Spain, 2017, pp. 516-521.

[27] Kroics K., Zemite L., Gaigals G. Analysis of advanced inverter topology for renewable energy generation and energy storage integration into AC grid. Proceedings of "16th International Scientific Conference Engineering for Rural Development”, May 24-27, Jelgava, Latvia, 2017, pp. 941-950.

[28] González-Santini N. S., Zeng H., Yu Y., Peng F. Z. Z-Source Resonant Converter With Power Factor Correction for Wireless Power Transfer Applications. IEEE Transactions on Power Electronics, vol. 31, no. 11, 2016, pp. 7691-7700.

[29] Huang L., Hu A. P., Swain A. K., Su Y. Z-Impedance Compensation for Wireless Power Transfer Based on Electric Field. IEEE Transactions on Power Electronics, vol. 31, no. 11, 2016, pp. 75567563.

[30]Zeng H., Peng F. Z. SiC-based Z-Source Resonant Converter with Constant Frequency and Load Regulation for EV Wireless Charger. IEEE Transactions on Power Electronics, vol. 32, no. 11, 2017, pp. 8813-8822.

[31] Wang T., Liu X., Tang H., Ali M. Modification of the wireless power transfer system with Zsource inverter. Electronics Letters, vol. 53, no. 2, 2017, pp. 106-108.

[32] Tianfeng W., Xin L., Houjun T., Yayun D., Xijun Y. Modeling and advanced control of wireless power transfer system with Z-source inverter. Proceedings of "IEEE 2nd Annual Southern Power Electronics Conference" (SPEC), December 5-8, Auckland, New Zealand, 2016, pp. 1-6.

[33] Surapaneni R. K., Das P. A Z-source Derived Coupled Inductor Based High Voltage Gain Microinverter. IEEE Transactions on Industrial Electronics, vol. 65, no. 6, 2018, pp. 5114-5124. 
[34] González-Santini N. S., Zeng H., Yu Y., Peng F. Z. Z-Source Resonant Converter With Power Factor Correction for Wireless Power Transfer Applications. IEEE Transactions on Power Electronics, vol. 31, no. 11, 2016, pp. 7691-7700.

[35] Liang W., Ge B., Liu Y., etc. Modeling, analysis, and impedance design of battery energy stored single-phase quasi-Z source photovoltaic inverter system. Proceedings of "IEEE Energy Conversion Congress" (ECCE), September 18-22, Milwaukee, USA, 2016, pp. 1-6.

[36] Kroics K., Zakis J., Suzdalenko A., Husev O., Tytelmaier K., Khandakji K. Operation possibility of grid connected Quasi-Z-Source Inverter with energy storage and renewable energy generation in wide power range. Proceedings of "IEEE First Ukraine Conference on Electrical and Computer Engineering" (UKRCON), May 29-June 2, Kyiv, Ukraine, 2017, pp. 564-569. 